\title{
Integrity of the alveolar-capillary barrier and alveolar surfactant system in smokers
}

\author{
B Schmekel, J A H Bos, A R Khan, B Wohlfart, B Lachmann, P Wollmer
}

\begin{abstract}
Background The permeability of the alveolar-capillary barrier to technetium$99 \mathrm{~m}$ labelled diethylenetriamine pentaacetate $\left({ }^{99 m}\right.$ Tc DTPA) is known to be greatly increased in smokers, but the underlying mechanism is poorly understood. Abnormal permeability of the alveolar epithelium as well as impaired surfactant function has been suggested. The purpose of this study was to examine transudation of urea and albumin into the alveoli and alveolar surfactant function in smokers and non-smokers and to relate these variables to the rate of alveolarcapillary transfer of ${ }^{99 \mathrm{~m}}$ Tc DTPA.
\end{abstract}

Methods Standardised bronchoalveolar lavage was performed and the yield of urea and albumin measured in the lavage fluid. The integrity of the alveolar surfactant system was assessed by measurement of the surface activity and of the yield of phospholipids in alveolar lavage fluid.

Results The mean decay constant for the pulmonary clearance of ${ }^{99 \mathrm{~m}}$ Tc DTPA was $0.028 / \mathrm{min}$ in the smokers and $0.009 / \mathrm{min}$ in the non-smokers. The recovery of albumin and urea in alveolar lavage fluid was very similar in the two groups. The surface activity of alveolar lavage fluid was lower in smokers than in non-smokers (minimum surface tension 37.9 versus $28.6 \mathrm{mN} / \mathrm{m}$ ) and the yield of phospholipids was reduced $(2.08$ versus $3.86 \mathrm{mg}$ ). The rate constant for the pulmonary clearance of ${ }^{99} \mathrm{~m}$ Tc DTPA correlated with the yield of phospholipids at bronchoalveolar lavage.

Conclusions The study shows that increased alveolar-capillary transfer of ${ }^{99 m}$ Tc DTPA in smokers is not accompanied by increased transudation of small or large molecules into the alveoli. The findings support the hypothesis that increased clearance of ${ }^{99 m}$ Tc DTPA in smokers is related to surfactant dysfunction.

Alveolar air is separated from pulmonary capillary blood by a delicate barrier, the integrity of which is crucially important for the liquid homoeostasis in the lung. The alveolarcapillary barrier comprises the alveolar surfactant system, the alveolar epithelium, the basement membrane, and the capillary endothelium. The functional integrity of the barrier can be studied by measurement of the transfer of solutes from the alveolus to the blood or the transudation of solutes from the capillaries to the air space.

The most common technique for studies of solute transfer from the air space to the blood is the measurement of pulmonary clearance of technetium-99m labelled diethylenetriamine penta-acetate $\left({ }^{99 \mathrm{~m}}\right.$ Tc DTPA). ${ }^{1}$ This hydrophilic molecule has a molecular weight of 490 daltons. The tracer is administered in aerosol form and subsequently the clearance of the tracer from the lungs is measured by external counting over the lungs. The rate of clearance reflects the transfer of the tracer across the alveolar-capillary barrier. Several groups have shown that the rate of pulmonary clearance of ${ }^{99 m}$ Tc DTPA is much faster in smokers than in non-smokers. ${ }^{2-6}$ The mechanism for the increased alveolar-capillary barrier permeability in smokers is not clear. It has been suggested that it reflects damage to the alveolar epithelium ${ }^{1}$ but also abnormal surfactant function in the alveoli. ${ }^{7}$

Indications of transudation of solutes from the capillaries to the alveoli can be obtained by analysis of solutes in bronchoalveolar lavage fluid. ${ }^{8}$ The yield of albumin in lavage fluid has thus been measured in smokers in attempts to assess the properties of the alveolar-capillary barrier. ${ }^{9-13}$ It has recently been shown that urea ( $\mathrm{mw} 60$ daltons) readily diffuses from blood and interstitial space into lavage fluid during the procedure. ${ }^{14-16}$ This suggests that the yield of urea in lavage effluent could be a suitable indicator of alveolar-capillary barrier permeability, provided that the dwell time of fluid in the alveoli is controlled. We are not aware of any studies of the yield of urea at bronchoalveolar lavage in smokers or of any attempt to correlate measurements of pulmonary clearance of ${ }^{99 \mathrm{~m}}$ Tc DTPA with indicators of increased alveolar-capillary barrier permeability at bronchoalveolar lavage in smokers.

It is well established that the yield of surfactant phospholipids in bronchoalveolar lavage effluents is reduced in smokers. ${ }^{12} 17$ The rapid pulmonary clearance of ${ }^{99 \mathrm{~m}}$ Tc DTPA has been suggested to be related to impaired surfactant function, but no studies of clearance in relation to measurements of phospholipids in lavage fluid have been carried out.

The purpose of this study was to relate measurements of pulmonary clearance of ${ }^{99 \mathrm{~m}} \mathrm{Tc}$ DTPA to indicators of alveolar-capillary barrier permeability and to indices of surfactant function obtained at bronchoalveolar lavage in normal smokers and non-smokers. 
Table 1 Characteristics (mean (SD) values) of the subjects studied and results of carboxyhaemoglobin measurements and spirometry

\begin{tabular}{lcc}
\hline & $\begin{array}{c}\text { Non-smokers } \\
(n=9)\end{array}$ & $\begin{array}{l}\text { Smokers } \\
(n=13)\end{array}$ \\
\hline Age (years) & $37(11)$ & $35(12)$ \\
Height (m) & $1 \cdot 79(0 \cdot 07)$ & $1 \cdot 82(0 \cdot 07)$ \\
Weight (kg) & $72(10)$ & $79(12)$ \\
Smoking history (pack years) & 0 & $17(12)$ \\
Carboxyhaemoglobin (\%) & $0 \cdot 62(0 \cdot 30)$ & $2 \cdot 58(1 \cdot 1)$ \\
Vital capacity (\% predicted) & $103(14)$ & $96(13)$ \\
FEV (\% predicted) & $106(14)$ & $100(10)$ \\
\hline
\end{tabular}

\section{Methods}

We studied 13 current male smokers and nine lifelong male non-smokers. None of the smokers had a history of chronic bronchitis. The physical characteristics of the two groups of subjects were similar (table 1). Physical examination showed nothing abnormal in any of the subjects.

\section{SPIROMETRY}

Spirometry, including measurement of vital capacity (VC) and forced expiratory lung volume in one second $\left(\mathrm{FEV}_{1}\right)$, was performed with a spirometer based on pneumotachography (Vitalograph Compact, Vitalograph Ltd, Buckingham). The results were related to predicted values. ${ }^{18}$

\section{PULMONARY CLEARANCE OF ${ }^{99 M}$ TC DTPA}

A solution of ${ }^{99 \mathrm{~m}} \mathrm{Tc}$ DTPA was prepared from a commercially available kit (Pentetate II, Amersham International, Amersham) and nebulised with an air jet nebuliser (UltraVent, Mallinckrodt Diagnostica, Petten, The Netherlands). The mass median diameter of the particles was $1.7 \mu \mathrm{m}$. The subjects inhaled the aerosol by quiet tidal breathing for one to two minutes while seated in front of a gamma camera (Maxicamera 400T, General Electric Company, Milwaukee, Wisconsin) until a count rate of about $2000 / \mathrm{s}$ had been reached. The subjects were then immediately placed in the supine position on a thin couch and the gamma camera placed under the couch to obtain an image of the lungs in the posterior view. The gamma camera was interfaced with a computer system and the measurements of radioactivity over the chest were stored in one minute frames for 30 minutes in a $64 \times 64$ image matrix. After about 20 minutes a small amount of ${ }^{99 \mathrm{~m}}$ Tc DTPA was injected intravenously to enable a correction for non-pulmonary radioactivity to be performed.

The measurements were analysed by selecting a region of interest enclosing both lungs and generating a time-activity curve. The correction for non-pulmonary radioactivity was performed as described by Barowcliffe et al, ${ }^{19}$ a background region being selected over the great vessels in the abdomen. An exponential function,

$$
\mathrm{A}=\mathrm{A}_{0} \times e^{-\mathrm{k} t},
$$

where $A_{0}$ is the count rate at time zero and $A$ is the radioactivity at any time, $t$, was fitted to the experimental data from 1 to 20 minutes. The slope was expressed as the decay constant (k).
BRONCHOALVEOLAR LAVAGE

Bronchoalveolar lavage was performed as previously described in detail. ${ }^{20}$ After premedication with morphine and scopolamine local anaesthesia was achieved with lignocaine. The fibreoptic bronchoscope (Olympus BF $1 \mathrm{~T}$ 10) was then loosely wedged in an anterior subsegment of the right middle or lower lobe. Three $50 \mathrm{ml}$ aliquots of tepid sterile saline were sequentially infused and then gently aspirated and collected in two separate containers. The first aliquot was considered to represent a bronchial wash. The following two aliquots were pooled and considered to be more representative of alveolar lavage fluid. The lavage procedure was standardised so far as possible and the time from infusion to aspiration of saline (dwell time) recorded. The lavage fluid was kept on ice until centrifuged $\left(4^{\circ} \mathrm{C}\right.$, $200 \mathrm{~g}$ ) for 10 minutes. The supernatant was removed from the cell pellet and kept frozen at $-70^{\circ} \mathrm{C}$ until it was analysed.

MEASUREMENT OF UREA AND ALBUMIN IN LAVAGE FLUID

The concentrations of urea and albumin were measured in bronchial wash fluid as well as in bronchoalveolar lavage fluid. In the bronchial wash fluid urea and albumin concentrations were measured in six non-smokers. Urea and albumin concentrations were measured in unconcentrated lavage fluid. ${ }^{21} 22$ The total amount of urea and albumin in the lavage fluid was calculated by multiplying the concentration by the volume of aspirated fluid. The plasma concentrations of urea and albumin were also measured in venous blood samples.

MEASUREMENT OF PHOSPHOLIPIDS IN LAVAGE FLUID

The concentration of phosphatidylcholine was measured in bronchoalveolar lavage fluid. Lipids were extracted twice with a twofold volume of chloroform:methanol (2:1) and once with chloroform. The extract was evaporated to dryness at $40^{\circ} \mathrm{C}$ in a rotary evaporator under vacuum. The residue was dissolved in $2.0 \mathrm{ml}$ of chloroform:methanol $(2: 1)$.

Phospholipids were separated by thin layer chromatography on $250 \mu \mathrm{m}$ thick gel plates (Kieselgel $60 \mathrm{~F}_{254}$, Merck). The solvent systems used were chloroform:methanol:water $(65: 25: 4)^{2324}$ and chloroform:methanol:acetic acid:water $(100: 60: 16: 8) .^{24}{ }^{25}$ To visualise the phospholipid fractions the chromatogram was exposed to iodine vapour. Phosphatidylcholine was localised in the chromatogram with the help of side standards of dipalmitoylphosphatidylcholine (Sigma Chemical Company, St Louis, Missouri) spotted on each plate. Three standards $(10,20$, and $30 \mu \mathrm{g}$ dipalmitoylphosphatidylcholine) were used. Spots in the chromatograms corresponding to dipamitoylphosphatidylcholine were quantified with a densitometer coupled with an integrator (wave length $366 \mathrm{~nm}$ ). The phosphatidylcholine recovered from smokers and non-smokers was essentially dipalmitoylphosphatidylcholine as confirmed by gas-liquid chromatography (containing over $73 \%$ palmitic acid). 
Figure 1 Rate constant for the pulmonary clearance of ${ }^{99 m}$ Tc DTPA in the two groups of subjects.

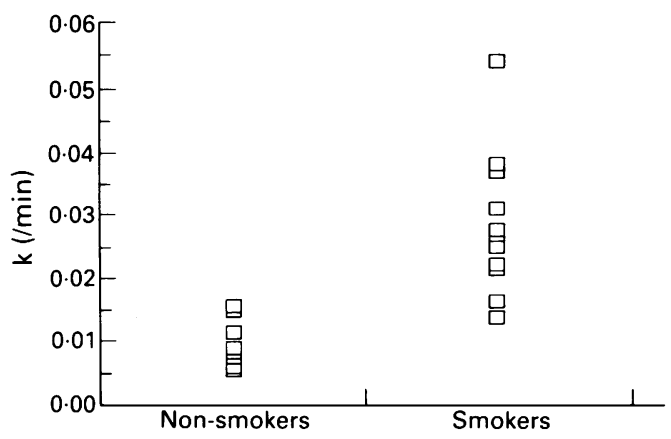

MEASUREMENT OF SURFACE ACTIVITY OF LAVAGE FLUID

The ability of bronchoalveolar lavage fluid to lower surface tension at an air-water interface was measured on a Wilhelmy balance (Wilhelmy Tensiometer, Biegler Electronic, Mauerbach, Austria); $0.8 \mathrm{ml}$ of lavage fluid was added to the saline filled trough and surface tension was recorded with a platinum plate while the area was altered by continuous cycling from $100 \%$ to $20 \%$ at a cycle speed of $0 \cdot 33 / \mathrm{min}$. Maximum $(\gamma \max )$ and minimum $(\gamma \mathrm{min})$ surface tensions were recorded during the fifth cycle.

\section{STATISTICAL ANALYSIS}

Results are presented as means with standard deviations in parentheses. Differences between groups were investigated with Student's $t$ test. Relation between variables was assessed by linear regression analysis. The level of significance was set at $\mathrm{p}=0.05$. The $95 \%$ confidence intervals for the differences between non-smokers and smokers (CI) and the corresponding $\mathrm{p}$ values are presented.

\section{Results}

There were no substantial differences in physical characteristics between smokers and non-smokers (table 1). There was a wide range in the cumulated tobacco consumption of the smokers. All subjects were essentially normal at spirometry, and there were no significant differences between the two groups.

Pulmonary clearance of ${ }^{99 \mathrm{~m}}$ Tc DTPA was much faster in the smokers than in the non-

Table 2 Mean (SD) urea and albumin concentrations in lavage fluid

\begin{tabular}{|c|c|c|}
\hline & $\begin{array}{l}\text { Non-smokers } \\
(n=9)\end{array}$ & $\begin{array}{l}\text { Smokers } \\
(n=13)\end{array}$ \\
\hline \multicolumn{3}{|l|}{ BRONCHIAL WASH } \\
\hline Recovery (ml) & $15(5)$ & $17(6)$ \\
\hline Dwell time (min) & $1.8(0.5)$ & $1.6(0.5)$ \\
\hline Urea concentration $(\mathrm{mmol} / \mathrm{l})$ & $0.03(0.01)$ & $0.06(0.04)$ \\
\hline Total urea (mmol) & $0.51(0.26)$ & $1 \cdot 19(1 \cdot 19)$ \\
\hline Albumin concentration & $1 \cdot 7(0.5)$ & $1.8(0 \cdot 6)$ \\
\hline Total albumin $(\mu \mathrm{mol})$ & $31(12)$ & $32(12)$ \\
\hline \multicolumn{3}{|c|}{ BRONCHOALVEOLAR LAVAGE FLUID } \\
\hline Recovery (ml) & $69(17 \cdot 4)$ & $68(13 \cdot 8)$ \\
\hline Dwell time (min) & $3 \cdot 7(0.9)$ & $3 \cdot 2(1 \cdot 1)$ \\
\hline Urea concentration $(\mathrm{mmol} / \mathrm{l})$ & $0.08(0.03)$ & $0.08(0.04)$ \\
\hline Total urea (mmol) & $5.04(1.52)$ & $5 \cdot 21(2 \cdot 2)$ \\
\hline $\begin{array}{l}\text { Albumin concentration } \\
(\mu \mathrm{mol} / \mathrm{l})\end{array}$ & $1.7(0.6)$ & $1 \cdot 7(0 \cdot 8)$ \\
\hline Total albumin $(\mu \mathrm{mol})$ & $116(54)$ & $119(57)$ \\
\hline
\end{tabular}

Table 3 Mean (SD) phosphatidylcholine concentrations and surface activity in bronchoalveolar lavage fluid

\begin{tabular}{|c|c|c|}
\hline & $\begin{array}{l}\text { Non-smokers } \\
(n=9)\end{array}$ & $\begin{array}{l}\text { Smokers } \\
(n=13)\end{array}$ \\
\hline $\begin{array}{l}\text { Phosphatidylcholine } \\
\text { concentration } \\
(\mathrm{mg} / \mathrm{ml})\end{array}$ & $60(31)$ & $30(9)$ \\
\hline $\begin{array}{l}\text { Total phosphatidylcholine } \\
\text { (mg) }\end{array}$ & $3.86(0 \cdot 12)$ & $2.08(0.65)$ \\
\hline$; \max (\mathrm{mN} / \mathrm{m})$ & $62 \cdot 1(6 \cdot 0)$ & $67 \cdot 2(3 \cdot 2)$ \\
\hline $\mathrm{min}(\mathrm{mN} / \mathrm{m})$ & $28 \cdot 6(5 \cdot 2)$ & $37 \cdot 9(5 \cdot 2)$ \\
\hline
\end{tabular}

smokers (fig 1). The decay constant ranged from 0.014 to $0.054 / \mathrm{min}$ with a mean of $0.028 /$ $\mathrm{min}$ in the smokers compared with a range from 0.006 to $0.016 / \mathrm{min}$ and a mean of $0.009 / \mathrm{min}$ in the non-smokers (CI -0.026 to -0.012 , $\mathrm{p}<0.001)$. There was thus a small overlap between the groups.

Dwell time and recovery of lavage fluid were very similar in the two groups of subjects (table $2)$. In the bronchial wash fluid the concentration and the total amount of urea were nonsignificantly higher in smokers than in nonsmokers. The concentrations of albumin in bronchial wash fluid were very similar in the two groups. In bronchoalveolar lavage fluid, the concentrations of both urea and albumin were virtually identical in non-smokers and smokers. The plasma concentrations of urea and albumin were also similar in non-smokers and smokers (urea $4.8(0.8)$ v $4.4(0.7) \mathrm{mmol} / \mathrm{l}$; albumin $0.68(0.03) v 0.65(0.04) \mathrm{mmol} / \mathrm{l})$.

The concentration of phosphatidylcholine in alveolar lavage fluid was measured in six nonsmokers and in 10 smokers. Measurements of surface activity were obtained in six non-smokers and in 11 smokers. The yield of phospholipids in bronchoalveolar lavage fluid was about twice as high in non-smokers as in smokers (table 3 ). The concentration (CI $-4 \cdot 0$ to $62.9 \mathrm{mg} / \mathrm{ml}, \mathrm{p}<0.05)$ and the total amount (CI 0.49 to $3.06 \mathrm{mg}, \mathrm{p}<0.01$ ) of phosphatidylcholine were significantly greater in non-smokers than in smokers. The surface activity of alveolar lavage fluid was also greater in non-smokers than in smokers (table 3 ). Both $\gamma \min$ and $\gamma \max$ were significantly lower in non-smokers than in smokers (CI -15.3 to

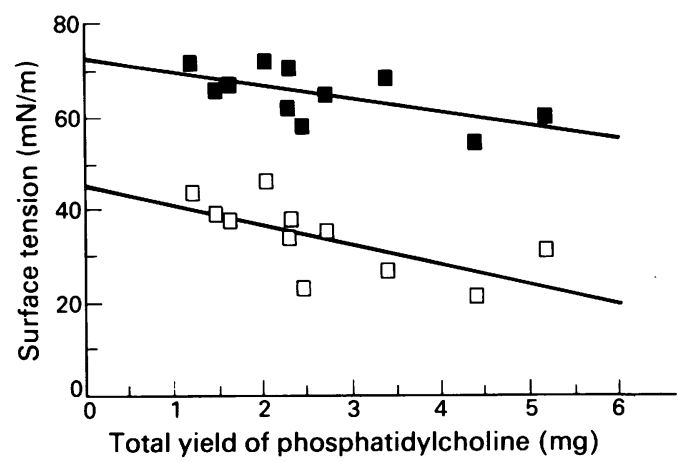

Figure 2 Maximum (filled symbols) and minimum (open symbols) surface tension of alveolar lavage fluid versus total yield of phosphatidylcholine in alveolar lavage fluid. There was a significant correlation for maximum $(r=-0.63)$ and for minimum $(r=-0.66)$ surface tension. 
Figure 3 Rate constant for the pulmonary clearance of ${ }^{99 m} T c D T P A$ versus the total yield of phosphatidylcholine in alveolar lavage fluid.

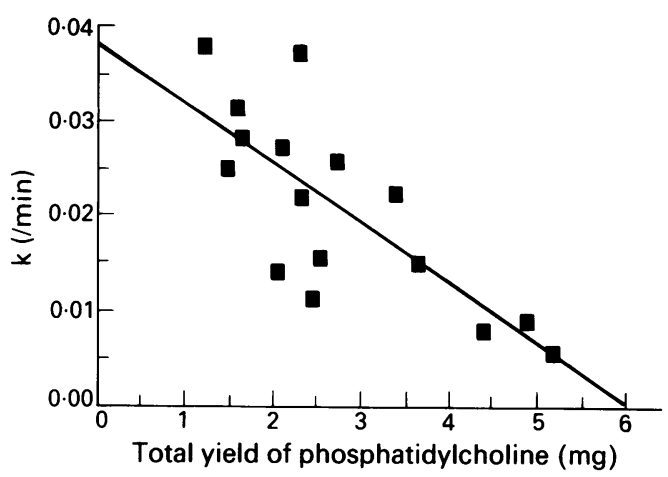

$3.4 \mathrm{mN} / \mathrm{m}, \mathrm{p}<0.01 ;$ CI $-11.7-1.3 \mathrm{mN} / \mathrm{m}$, $\mathrm{p}<0.05)$.

Measurements of the yield of phosphatidylcholine and measurements of surface activity of bronchoalveolar lavage fluid may be regarded as indicators of the functional integrity of the surfactant system, and we were interested in possible correlations between the measurements. We found the total amount of phosphatidylcholine recovered to be inversely correlated with $\gamma \max (r=-0.63, p<0.05)$ and $\gamma \min (r=-0.66, p<0.05$; fig 2$)$.

We found several correlations between the rate of pulmonary clearance of ${ }^{99 \mathrm{~m}} \mathrm{Tc}$ DTPA and variables reflecting the properties of the surfactant system. The rate constant $k$ was thus correlated inversely with the lavage fluid concentration of phosphatidylcholine $(r=-0.62$, $\mathrm{p}<0.05)$ and with the total amount of phosphatidylcholine recovered $(r=0.77, p<0.01$; fig 3).

\section{Discussion}

The alveolar-capillary barrier comprises the alveolar surfactant system, the alveolar epithelium, the basement membrane, and the capillary endothelium. In studies of fluid filled lungs the alveolar epithelium has been shown to be much less permeable to small water soluble molecules than is the capillary endothelium, whether the tracer substance is introduced into the alveolar space or into the blood. ${ }^{26}{ }^{99 \mathrm{~m}}$ Tc DTPA is a hydrophilic compound and is considered to be transported by simple diffusion via the paracellular route. The increased rate of clearance observed in smokers is often interpreted, in accordance with studies of solute transfer in fluid filled lungs, as representing a high permeability of the alveolar epithelium to ${ }^{99 \mathrm{~m}}$ Tc DTPA. As the alveolar epithelium is the major barrier to solute flux also from the blood into the alveoli, ${ }^{1426}$ increased permeability of the epithelium might be expected to cause increased transfer of solutes into bronchoalveolar lavage fluid. When a tracer such as ${ }^{99 m}$ Tc DTPA is introduced into the alveoli in aerosol form the alveolar surfactant system is functionally intact, unlike in the fluid filled lung. The pulmonary clearance of ${ }^{99 \mathrm{~m}} \mathrm{Tc}$ DTPA is increased in experimental states of surfactant dysfunction ${ }^{27} 28$ and reduced by experimentally increased alveolar surfactant content. ${ }^{29}$ Recent speculations have suggested that the rapid clearance in smokers is related to abnormal surfactant function. ${ }^{7}$ This study was designed to investigate the relation between pulmonary clearance of ${ }^{99 \mathrm{~m}} \mathrm{Tc}$ DTPA and indices of solute transfer from the pulmonary capillaries and of alveolar surfactant function from fluids obtained via bronchoalveolar lavage. We found that, whereas the transfer of ${ }^{99 \mathrm{~m}}$ Tc DTPA from the alveoli to the blood is much faster in smokers than in non-smokers, there is no indication of increased leakage of urea or albumin from the pulmonary circulation or interstitial fluid to the alveoli during bronchoalveolar lavage in smokers. Indices of alveolar surfactant function are abnormal in smokers and correlate with the rate of pulmonary clearance of ${ }^{99 \mathrm{~m}} \mathrm{Tc}$ DTPA.

The yields of urea and albumin in bronchoalveolar lavage fluid have long been used as indicators of the permeability of the air-blood barrier. ${ }^{8}$ Urea is a small molecule and is able to diffuse through intact cell membranes. ${ }^{30}$ It is well established that urea diffuses into lavage fluid in appreciable amounts during a few minutes of fluid dwell time in the alveoli. ${ }^{14-1631}$ The concentration of urea in alveolar lavage fluid has previously been shown to be increased in patients with interstitial lung disease. ${ }^{1520} \mathrm{We}$ found the alveolar lavage fluid concentration of urea to be about $2 \%$ of the serum concentration in both smokers and non-smokers. A first approximation of the rate of transfer of urea from blood and interstitial tissue can be obtained from a simple two compartment model on the assumption of first order kinetics (appendix). The calculations result in similar rate constants in smokers and non-smokers. Furthermore, the rate constants for urea are of the same order of magnitude as the rate constants for ${ }^{99 \mathrm{~m}} \mathrm{Tc}$ DTPA found in the non-smokers. The main barrier for the transport of urea from blood to the fluid filled alveolus is the alveolar epithelium. ${ }^{1426}$ If the main mechanism for the increased rate of alveolar-capillary transfer of ${ }^{99 \mathrm{~m}} \mathrm{Tc}$ DTPA in the smokers were increased permeability of the alveolar epithelium, the rate of transfer of urea from blood to air space would also appear likely to be increased.

The rate of transfer of albumin from blood into the fluid filled alveolus is much lower than that of urea ${ }^{1426}$ and very little albumin diffuses into alveolar lavage fluid under normal conditions. Unless there are gross changes in the permeability of the alveolar-capillary barrier, the use of albumin concentration in lavage fluid as an index of permeability relies on changes in the amount of albumin in the alveoli at steady state. Studies of the yield of albumin at bronchoalveolar lavage in smokers have given conflicting results. Part of the discrepancies may be related to the lavage technique: different amounts of lavage fluid and different numbers of aliquots have been used, and some investigators pool all aliquots whereas others keep them separate. The yield of albumin is also expressed in different ways, which makes comparisons difficult. Low et $a l^{12}$ found the ratio between the concentration of albumin in plasma and lavage fluid to be significantly lower in smokers than in non-smokers. Bell et $a^{\beta^{2}}$ 
found the total amount of protein recovered by lavage to be considerably increased in smokers. In contrast, Reynolds and Newball ${ }^{9}$ and Warr et $a l^{10}$ found no differences in the yield of albumin between smokers and non-smokers, and Banks et $a l^{13}$ found a tendency for the yield of albumin to be reduced in smokers. Thompson $e t$ al $^{11}$ measured albumin concentration in bronchial and alveolar lavage fluid separately in normal smokers and non-smokers as well as in patients with chronic bronchitis. They found no differences between normal smokers and non-smokers. In the patients with chronic bronchitis albumin concentration was increased in the bronchial, but reduced in the alveolar, lavage fluid. Our finding of similar albumin yields in normal smokers and nonsmokers at bronchoalveolar lavage thus agrees with the results of most previous studies and gives no indication of increased transudation of albumin from the pulmonary capillaries.

A low yield of surfactant phospholipids from smokers was first described by Finley and Ladman $^{17}$ and subsequently by Low et al. ${ }^{12}$ In an experimental study Le Mesurier et $a l^{33}$ showed the lavage yield of phospholipids to be reduced in rats exposed to cigarette smoke. Abnormal surface activity of lavage fluid from smokers has been described by Cook and Webb. ${ }^{34}$ In general agreement with these studies, we found a lower yield of phospholipids and a lower surface activity of alveolar lavage fluid in smokers than in nonsmokers. Surface tension, as measured in this study, may reflect quantitative or qualitative abnormalities (or both) of alveolar surfactant. Correlation analysis showed the variance in phospholipid recovery to explain some $40 \%$ of the variance in the maximum and minimum surface tensions of lavage fluid. This may indicate that there are also qualitative differences in the properties of alveolar surfactant between smokers and non-smokers. Some support for this idea is provided by the finding that cigarette smoke impairs surface activity of lavage fluid in vitro. ${ }^{35}$

The rate constant for the alveolar-capillary transfer of ${ }^{99 \mathrm{~m}} \mathrm{Tc}$ DTPA correlated with both the phospholipid concentration and the surface activity of lavage fluid. These correlations do not, of course, prove a causal relation between surfactant dysfunction and pulmonary clearance of ${ }^{99 \mathrm{~m}} \mathrm{Tc}$ DTPA. Taken together with the findings of normal lavage fluid concentrations of urea and albumin they do, however, support the hypothesis that abnormal clearance of ${ }^{99 \mathrm{~m}}$ Tc DTPA in smokers could be related more to surfactant dysfunction than to permeability of the alveolar epithelium. There are several possible mechanisms whereby surfactant dysfunction could influence the absorption of ${ }^{99 m}$ Tc DTPA. ${ }^{36}$ Surfactant could affect the spreading of the tracer in the aqueous hypophase in the alveolus. If permeability varies within the alveolus - for example, is greater in the corners-this would affect the clearance rate.

This study suggests that the rate of absorption of small solutes across the alveolarcapillary barrier may increase without a cor- responding increase in transudation of solutes - that is, that the change in permeability is to some extent unidirectional. Unidirectional permeability changes have also recently been reported for the mucosal barrier of the upper airways. Greiff $e t a l^{37}{ }^{38}$ have shown the rate of absorption of small hydrophilic solutes to be unchanged during histamine induced plasma exudation in experimental animals and in man.

In summary, we found a higher rate of alveolar-capillary transfer of ${ }^{99 \mathrm{~m}}$ Tc DTPA in smokers than in non-smokers, but no indication of increased transfer of urea or albumin from the blood into the alveoli at lavage. The rate of pulmonary clearance of ${ }^{99 \mathrm{~m}}$ Tc DTPA correlated with indices of surfactant function obtained at alveolar lavage, supporting the hypothesis that increased clearance of ${ }^{99 \mathrm{~m}} \mathrm{Tc}$ DTPA in smokers is related to surfactant dysfunction.

\section{Appendix}

The rate of diffusion of urea from blood and interstitial fluid into alveolar lavage fluid was estimated in a simple two compartment model. Urea is assumed to diffuse from a body water compartment with a constant concentration of urea corresponding to the plasma concentration into an alveolar lavage fluid compartment. The initial urea concentration in the alveolar compartment is postulated to be zero. The increase in urea concentration of lavage fluid $\left(U_{1}\right)$ with time $(t)$ is described by

$$
\mathrm{U}_{1}=\mathrm{U}_{\mathrm{p}}\left(1-e^{-\mathrm{k} r}\right),
$$

where $U_{p}$ is the plasma concentration of urea and $k$ the rate constant. Using the mean values of the lavage fluid and plasma concentrations of urea found in non-smokers yields a rate constant of 0.0047 . The corresponding value for smokers is 0.0057 .

We thank Dr Per Venge of the department of clinical chemistry, University of Uppsala, for measuring plasma and lavage fluid concentrations of urea and albumin. This study was supported by grants from the Swedish Medical Research Council (No 2872), the Swedish Heart and Lung Foundation, the Swedish
Work Environment Fund, and Astra Draco AB.

1 Barrowcliffe MP, Jones JG. Solute permeability of the alveolar-capillary barrier. Thorax 1987;42:1-10.

2 Jones JG, Lawler P, Crawley JCW, Minty BD, Hulands G, Veall $\mathrm{N}$. Increased alveolar epithelial permeability in cigarette smokers. Lancet 1980;i:66-8.

3 Dusser DJ, Minty BD, Collignon MAG, Hinge D, Barritault LG, Huchon GJ. Regional respiratory Barritault LG, Huchon GJ. Regional respiratory
clearance of aerosolized ${ }^{4 m}$ Tc DTPA: posture and smokclearance of aerosolized
ing effects. J Appl Physiol 1986;60:2000-6.

4 Huchon GJ, Russel JA, Barritault LG, Lipavsky A, Murray JF. Chronic air-flow limitation does not increase respiratory epithelial permeability assessed by aerosolized solute, but smoking does. Am Rev Respir Dis 1984;130: 457-60.

5 Kennedy SM, Elwood RK, Wiggs BJR, Paré PD, Hogg JC. Increased airway mucosal permeability in smokers. $\mathrm{Am}$ Rev Respir Dis 1984;129:143-8.

6 O'Byrne PM, Dolovich M, Dirks R, Roberts RS, Newhouse MT. Lung epithelial permeability: relation to nonspecific airway responsiveness. $J$ Appl Physiol 1984;57:77-84.

7 Wollmer P. Transfer of ${ }^{40 \mathrm{~m}}$ Tc DTPA, lung surfactant and lung injury: a review of the literature. Appl Cardiopulm lung injury: a review of the
Pathophysiol $1991 ; 4: 155-60$.

8 Reynolds HY. Bronchoalveolar lavage. Am Rev Respir Dis 1987;135:250-63.

9 Reynolds HY, Newball HH. Analysis of proteins and respiratory cells obtained from human lungs by bronchial lavage. J Lab Clin Med 1974;84:559-73.

10 Warr GA, Martin RR, Sharp PM, Rossen RD. Normal human bronchial immunoglobulins and proteins. Effect of cigarette smoking. Am Rev Respir Dis 1977;116:25-30.

11 Thompson AB, Daughton D, Robbins RA, Ghafouri MA, 
Oehlerking M, Rennard SI. Intraluminal airway inflammation in chronic bronchitis. Am Rev Respir Dis 1989;140:1527-37.

12 Low RB, Davis GS, Giancola MS. Biochemical analyses of bronchoalveolar lavage fluids of healthy human volunteer smokers and nonsmokers. Am Rev Respir Dis 1978; 118:863-75.

13 Banks DE, Morgan JE, Deshazo RD, Weissman D; Rodrigues FH, Barkman HW, et al. Reliability of cell counts and protein determinations in serial bronchoalveolar lavage procedures performed on healthy volunteers. Am J Med Sci 1990;300:275-82.

14 Effros RM, Mason GR, Silverman P, Reid E, Hukkanen J. Movements of ions and small solutes across endothelium and epithelium of perfused rabbit lungs. J Appl Physiol 1986;60:100-7.

15 van de Graaf EA, Jansen HM, Weber JA, Koolen MGJ, Out TA. Influx of urea during bronchoalveolar lavage depends on the permeability of the respiratory membrane. Clin Chim Acta 1991;196:27-40.

16 Schmekel B, Venge P. The distribution of myeloperoxidase (MPO), eosinophil cationic protein (ECP), albumin and urea in sequential broncho-alveolar lavage. Eur Respir $J$ 1991;4:517-23.

17 Finley TN, Ladman AJ. Low yield of pulmonary surfactant in cigarette smokers. $N$ Engl J Med 1972;286:223-7.

18 Berglund E, Birath G, Bjure J, Grimby G, Kjellmer I, Sandqvist $\mathrm{L}$, et al. Spirometric studies in normal subjects. I. Forced expirograms in subjects between 7 and 70 years of age. Acta Med Scand 1963;173:185-92.

19 Barrowcliffe MP, Otto C, Jones JG. Pulmonary clearance of ${ }^{99 m}$ Tc DTPA: influence of background activity. J Appl Physiol 1988;64:1045-9.

20 Schmekel B, Wollmer P, Venge P, Linden M, Blom-Bulow B. Transfer of ${ }^{99 m}$ Tc DTPA and bronchoalveolar lavage findings in patients with asymptomatic extrinsic allergic alveolitis. Thorax 1990;45:525-9.

21 Gutman I. Urea. In: Bergmeyer HU, ed. Methods of enzymatic analysis. Weinheim: Verlag Chemie Weinheim, 1977:1791.

22 Lizana J, Hellsing K. Polymer enhancement of automated immunological nephelometric analysis as illustrated by determination of urinary albumin. Clin Chem 1974;20: 415-20.

23 Woelk H, Goracci G, Gaiti A, Pocellati G. Phospholipase A1 and $A 2$ activities of neuronal and glial cells of the rabbit brain. Hoppe-Seylers Z Physiol Chem 1973;354:729-36.

24 Balzer H, Khan AR. The different fatty acid composition of lecithins in the sarcoplasmic reticulum vesicles and the membranes of adrenal chromaffin granules. N-S Arch Pharmacol 1975;291:319-33.

25 Madeira VMC, Antunes-Madeira MC. Chemical composition of sarcolemma isolated from rabbit skeletal muscle. Biochim Biophys Acta 1973;298:230-8.

26 Staub NC. Pulmonary edema. Physiol Rev 1974;54:678-811.

27 Evander E, Wollmer P, Jonson B, Lachmann B. Pulmonary clearance of inhaled ${ }^{99 m}$ Tc DTPA: effects of surfactan depletion by lung lavage. J Appl Physiol 1987;62:1611-4.

28 Evander E, Wollmer P, Jonson B. Pulmonary clearance of inhaled ${ }^{99 m}$ Tc DTPA: effect of the detergent dioctyl sodium sulfosuccinate in aerosol. Clin Physiol 1988;8 105-11.

29 Bos JAH, Wollmer P, Bakker W, Hannappel E, Lachmann B. Clearance of ${ }^{99 \mathrm{~m}} \mathrm{TcDTPA}$ and experimentally increase alveolar surfactant content. $J$ Appl Physiol (in press).

30 Macey RI. Transport of water and urea in red blood cells. Am J Physiol 1984;246:C195-203.

31 van de Graaf EA, Jansen HM, Weber JA, Koolen MGJ, Ou TA. Influx of urea during bronchoalveolar lavage depends on the permeability of the respiratory membrane. Clin Chim Acta 1991;196:27-40.

32 Bell DY, Haseman JA, Spock A, McLennan G, Hook GER. Plasma proteins of the bronchoalveolar surface of the lungs of smokers and nonsmokers. Am Rev Respir Dis lungs of smokers

33 Le Mesurier SM, Stewart BW, Lykke AW. Injury to type-2 pneumocytes in rats exposed to cigarette smoke. Environ Res $1981 ; 24: 207-17$

34 Cook WD, Webb WR. Surfactant in chronic smokers. Ann Thorac Surg 1966;2:327-33.

35 Webb WR, Cook WA, Lanius JW, Shaw RR. Cigarette smoke and surfactant. Am Rev Respir Dis 1967;95:244-7. 36 Effros RM. Permeability of the blood-gas barrier. In Chrystal RG, West JB, eds. The lung: scientific foundations. New York: Raven Press, 1991:1163-76.

37 Greiff L, Erjefält I, Wollmer P, Pipkorn U, Persson CGA Effects of histamine, ethanol and a detergent on exudation and absorption across guinea pig airway mucosa in vivo. Thorax 1991;46:700-5.

38 Greiff L, Wollmer P, Pipkorn U, Persson CGA. Absorption of ${ }^{51} \mathrm{Cr}$ EDTA across the human nasal airway barriers in the presence of topical histamine. Thorax 1991;46:630-2. 